\title{
O Processo de Referenciação na Produção TEXTUAL DE ADOLESCENTES SURDOS
}

\author{
Reference process in written language \\ productions of deaf teenagers
}

\author{
Ana Cristina Guarinello* \\ Ana Paula Santana* \\ Giselle Massi* \\ Ana Paula Berberian** \\ Maria Cristina da Cunha Pereira"**
}

INTRODUÇÃo

O objetivo deste estudo é analisar produções escritas de sujeitos surdos à luz do conceito de referenciação desenvolvido pela lingüística textual, mais especificamente proposto por Koch e Marcuschi (2002).

De início convém explicitar que estudos que buscam analisar objetivamente as produções escritas de sujeitos surdos apresentam-se escassos, havendo poucas pesquisas envolvidas com o conhecimento que tais sujeitos têm sobre a compreensão e a produção de textos. Contudo, a relevância do desenvolvimento de investigações em torno desse conhecimento vem sendo, gradativamente, percebida nas pesquisas em psicologia, fonoaudiologia, lingüística e, também, em educação, segundo Meirelles e Spinillo (2004). Tais estudos evidenciam, recorrentemente, limitações apresentadas pelos sujeitos surdos no processo de apropriação da língua portuguesa em sua modalidade escrita.

Nessa direção, Kyle (1981) afirma que os surdos têm dificuldades para ler e escrever, as quais ficam evidentes com relação à conjugação verbal, à falta de artigos e pronomes e aos verbos auxiliares, além dos

\footnotetext{
" Professora do Departamento de Fonoaudiologia e Mestrado em distúrbios da comunicação pela Universidade Tuiuti do Paraná.

** Pós-Doutorado em Lingüística pela Universidade Federal do Paraná e Professor adjunto na Universidade Tuiuti do Paraná.

*** Professora titular da Pontifícia Universidade Católica de São Paulo e lingüista da
} Divisão de Educação e Reabilitação dos Distúrbios da Comunicação, da PUCSP. 
erros de omissão, substituição, adição de vocábulos e desorganização na ordem das palavras. Pereira e Oliveira (1999), também, apontam para o fato de os surdos apresentarem dificuldades com aspectos relacionados à gramática do português escrito.

Um estudo desenvolvido por Fernandes (1990), com quarenta surdos com mais de dezoito anos e que já haviam concluído, no mínimo, a $4 .^{a}$ série do Ensino Fundamental, denuncia o uso restrito que tal população faz de diferentes recursos da Língua Portuguesa, para ler e compreender textos. Segundo Fernandes, esse uso restrito evidencia-se a partir da considerável limitação de seus informantes no que se refere ao domínio da estrutura da língua, restrições lexicais, falta de consciência de processos de formação de palavras, uso inadequado de verbos em suas conjugações, tempos e modos, uso inadequado de preposições, omissão de conectivos em geral e verbos de ligação, troca do verbo ser por estar, falta de domínio e uso restrito de certas estruturas de coordenação e subordinação. Para a autora, essa situação é um reflexo do processo insuficiente ou inadequado de educação desses surdos, os quais devem ter amplo domínio da língua de sinais, pois só assim, no seu ponto de vista, o acesso deles à Língua Portuguesa será efetivo.

O trabalho de Góes (1999) caracteriza textos produzidos por surdos e analisa suas construções atípicas a partir de uma investigação que faz junto a alunos do ensino supletivo que haviam passado por um longo período de escolarização. Góes (1999), da mesma forma que Fernandes (1998), verifica vários desvios no uso de regras de construção do português, tais como: uso inadequado ou omissão de preposições, terminação verbal nãocorrespondente à pessoa do verbo, inconsistência de tempo e modo verbais, flexão inadequada de gênero em adjetivos e artigos, uso incorreto do pronome pessoal do caso oblíquo, entre outros.

Além disso, Góes identificou nos textos analisados problemas relativos a aspectos de coesão, principalmente no que concerne à referencialidade e à progressão temática, visto que estes aspectos tendem a resultar em prejuízos na coerência do texto. Primeiramente, identificou alguns problemas com relação a instâncias de referencialidade ambígua, que se referem à maneira de inserção de nomes e pronomes no enunciado, o que pode causar prejuízo na interpretação do referente. O segundo tipo de prejuízo para interpretação dos enunciados decorre da escolha lexical indevida, isto é, da inclusão de palavras com significado não convencional ou uso de palavras "criadas".

Essa autora chama atenção para o fato de os textos analisados terem sido produzidos sob influência das regras da língua de sinais. Por isso, sublinha, da mesma forma que Rodrigues Silva (1998), a necessidade de conceder um espaço efetivo à Língua Brasileira de Sinais no atendimento educacional do 
surdo. Porém, para que isso ocorra, é preciso, segundo Góes, encorajar a expansão de projetos que tenham por meta a capacitação dos professores ouvintes, a formação de professores surdos, o incentivo ao trabalho pedagógico orientado para o uso da língua de sinais e a ampliação de pesquisas sobre o conhecimento dessa língua.

Outra pesquisa que busca analisar aspectos coesivos dos textos escritos foi desenvolvida por Silva (2001). Essa pesquisadora analisou a estruturação de textos de oito alunos surdos em uma faixa etária entre dezesseis e vinte e um anos, que freqüentaram até a $4 .{ }^{a}$ série de uma escola especial, sendo que todos se comunicavam basicamente por meio da Língua Brasileira de Sinais. Sua análise considerou a coesão textual e as habilidades que o surdo exposto à língua de sinais dispõe para a produção do texto.

Na mesma trilha de Fernandes e Góes, Silva constatou a interferência da Língua Brasileira de Sinais nas produções escritas dos sujeitos surdos. Ela afirmou que os textos escritos dos surdos envolvidos com a língua de sinais não apresentam as mesmas características dos textos de um falante de português, mas de um sujeito que tem o português como segunda língua. Para Silva, as dificuldades encontradas pelos surdos, com relação à sua escrita, não devem ser tomadas como um empecilho, mas podem ser uma referência pedagógica para o trabalho com a escrita da língua portuguesa como segunda língua.

Os estudos citados demonstram que o fato de o surdo não receber informações auditivas não é o único a interferir nas suas práticas de leitura e produção de textos em português, mas, sobretudo, a questão de sua língua fundadora - a língua de sinais - não estar participando ativamente no processo de compreensão e produção de seus textos escritos. A língua de sinais, portanto, não pode ser desconsiderada quando avaliamos e trabalhamos com a leitura e a escrita dos surdos.

Um outro fator importante e pouco discutido na análise da escrita do surdo é a referenciação. Entendemos que usos de estratégias de referenciação são fundamentais na produção da compreensão e da elaboração de textos por parte de ouvintes e devem ser, da mesma forma, considerados cruciais nas construções textuais desenvolvidas pelos surdos. Cabe esclarecer que a progressão referencial ou referenciação é um dos aspectos da textualidade que dá estabilidade e continuidade ao texto, sendo fator relevante para a coerência discursiva.

De acordo com Koch e Marcuschi (1998), a referenciação é um processo que se realiza negociadamente no discurso resultando na construção de referentes. Por isso, referir não é uma atividade que se confunde com "etiquetar" um mundo indicialmente designado, mas uma atividade discursiva, na qual os referentes passam a ser objetos de discurso e não realidades independentes. Isso não significa que tudo se transforma em 
panacéia subjetiva, mas que a discretização do mundo pela linguagem apresenta-se como fenômeno discursivo.

Tomando a língua como heterogênea, variável, socialmente constituída e entendendo o mundo como indefinido, a referenciação passa a ser encarada como um processo que se configura no uso da língua, ou seja, como um processo discursivo e os referentes como objetos do discurso. Assim, na escrita de textos, a referência é concebida como atividade que ocorre no interior do discurso, resultante da negociação entre os participantes do processo discursivo e as cadeias referenciais como mecanismos por meio dos quais uma informação é apresentada e mantida no texto, de tal forma que o entendimento desse texto seja possível, segundo Marcuschi (1998) e Mondada e Dubois (1995). Portanto, nesse trabalho sobre a escrita de surdos, a referência é concebida como processo resultante da negociação estabelecida entre interlocutores no interior do discurso; e as cadeias referenciais são tomadas como mecanismos por meio dos quais uma informação é apresentada e mantida no texto, contribuindo para o entendimento desse texto.

Koch e Marcuschi (2002) afirmam que: a) a referência é, sobretudo, um problema que diz respeito às operações efetuadas pelos sujeitos à medida que o discurso se desenvolve; b) o discurso constrói aquilo a que faz remissão, ao mesmo tempo em que é tributário dessa construção; c) e, finalmente, eventuais modificações, quer físicas, quer de qualquer outro tipo, sofridas "mundanamente" ou mesmo predicativamente por um referente, não acarretam necessariamente uma recategorização lexical no discurso.

Para esses autores, sendo a referenciação um caso geral de operação dos elementos designadores, todos os casos de progressão referencial estão baseados em algum tipo de referenciação, não importando se são os mesmos elementos que recorrem ou não. Deste modo, referir é uma atividade de designação realizável com a língua sem implicar uma relação especular línguamundo; remeter é uma atividade de processamento indicial na co-textualidade; retomar é uma atividade de continuidade de um núcleo referencial, seja numa relação de identidade ou não.

Além disso, conforme Koch e Marcuschi (2002), a progressão referencial não se dá necessariamente pela retomada, mas sempre por algum tipo de remissão. O primeiro elemento referido é chamado de fonte, e o elemento lingüístico a que ele remete (retomando-o ou não) é chamado de anáfora. A anáfora é uma estratégia de textualização que não supõe continuidade linear de referentes.

Outros termos utilizados por Koch e Marcuschi (2002) são a recategorização e a co-significação. Esses dois aspectos têm fundamental importância nos processos de referenciação e da progressão textual. 0 primeiro funda-se em um tipo de remissão vinculada a um aspecto 
co(n)textual antecedente, que pode ser tanto um item lexical como uma idéia que opera como espaço informacional para a inferenciação. E o segundo, relacionado à co-significatividade se dá como uma relação léxico-semântica.

\section{MÉTODO}

Participantes

O corpus deste estudo é composto por dezesseis produções escritas, elaboradas ao longo de dois anos, por quatro sujeitos surdos, com idade entre onze e quinze anos. Na época da coleta, eles freqüentavam séries do Ensino Fundamental em escolas regulares de Curitiba ou da região metropolitana, com exceção de um sujeito que freqüentava uma classe especial dentro de uma escola regular. Esses sujeitos eram atendidos semanalmente pela fonoaudióloga, pesquisadora principal desse trabalho. Todos os participantes apresentavam perda auditiva profunda, bilateral, congênita. Além disso, todos eles eram usuários de Libras (Língua Brasileira de Sinais) e da leitura orofacial.

\section{MATERIAL}

Folhas de papel, lápis, canetas e diferentes materiais escritos: jornais, gibis, livros, revistas, entre outros.

\section{PROCEDIMENTO}

As dezesseis produções textuais foram coletadas durante sessões de terapias fonoaudiológicas individuais, nas quais a investigadora foi coautora dos textos elaborados. A coleta dos dados da pesquisa baseou-se em duas estratégias: 1) a investigadora utilizava na terapia textos escritos de diferentes gêneros, tais como: contos, fábulas, notícias, receitas, cartas, bilhetes, poesias, entrevistas. Ela lia em conjunto com os sujeitos e interferia sempre que solicitada. Isto é, quando eles não entendiam algum vocábulo ou o sentido de uma sentença, ela explicava por meio da língua de sinais. Após a leitura e a explicação do texto, solicitava que os sujeitos escrevessem algo a respeito do que haviam lido; 2) a investigadora e os surdos conversavam sobre assuntos do interesse deles e, na seqüência, eles eram solicitados a escrever sobre o tema que haviam conversado. Em todas as sessões, a escrita foi enfatizada em contextos significativos, enfim, em produções de diferentes gêneros discursivos, a partir das quais os surdos interiorizavam a 
Língua Portuguesa, percebendo sua funcionalidade.

Convém esclarecer que, embora nossa análise esteja vinculada a dezesseis textos produzidos pelos sujeitos da pesquisa, pela impossibilidade de apresentar a análise de todos eles, optamos por explicitar apenas quatro produções textuais. Contudo, em nossos resultados são considerados, em termos quantitativos e qualitativos, dezesseis textos de diferentes gêneros discursivos. Portanto, cabe ressaltar que estão sendo privilegiados textos entendidos como resultantes de um processo ininterrupto de negociação estabelecida entre interlocutores no interior do discurso, de acordo com Marcuschi (2001).

Além disso, ressaltamos que o procedimento de análise usado em nossa investigação está pautado na proposta de Koch e Marcuschi (2002), a qual foi adaptada por Guarinello (2004), que considerou recursos e estratégias usados por surdos nos processos de referenciação, conforme o Quadro 1, apresentado na seqüência:

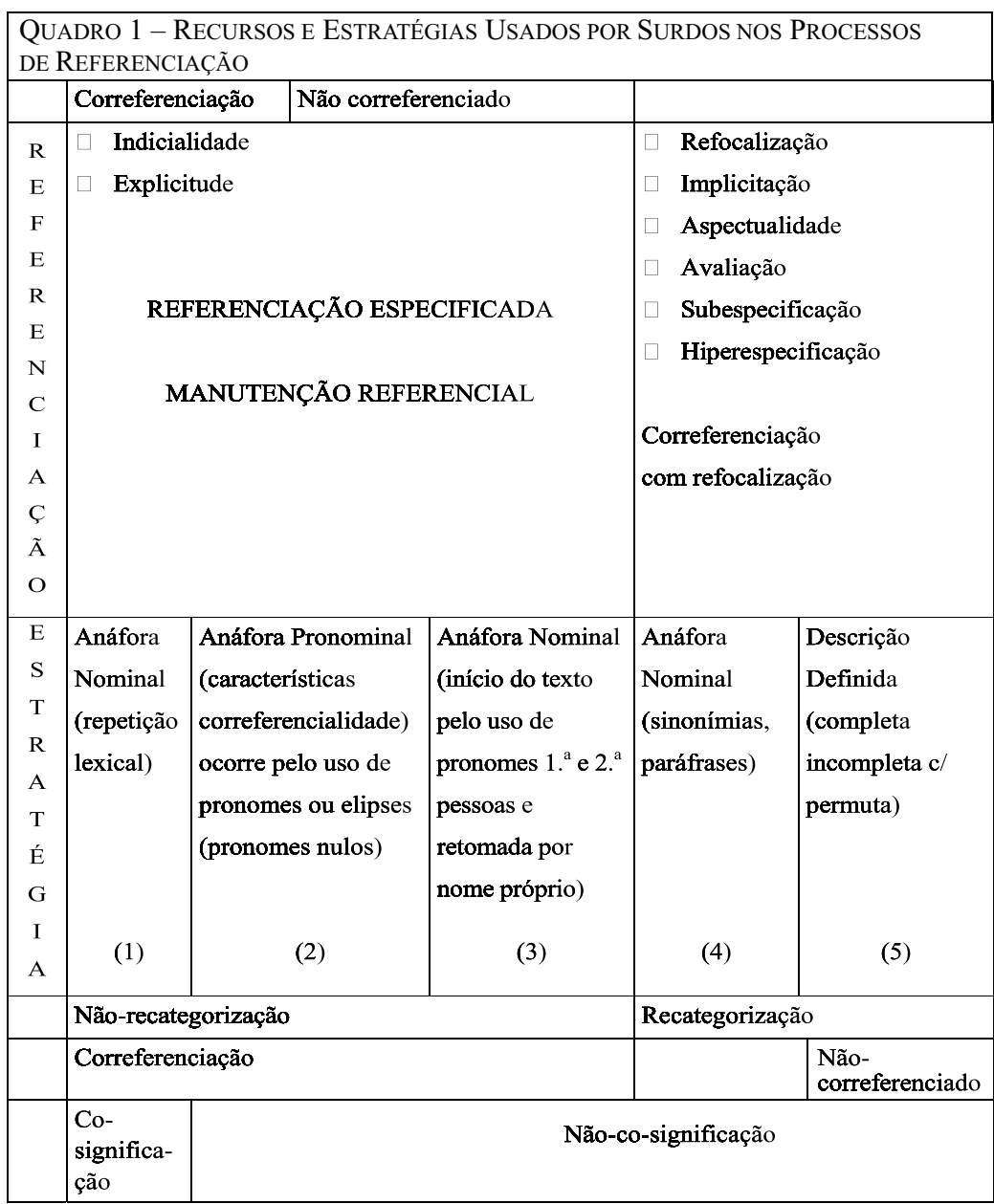


Esse quadro fundamenta a análise das estratégias de referenciação apresentadas nos textos dos sujeitos desta pesquisa. A seguir, a título de ilustração, será apresentado um exemplo da utilização de cada uma das estratégias explicitadas no Quadro 1, de acordo com Guarinello (2004), que considerou textos produzidos por surdos:

\section{Exemplo 1: Anáfora Nominal}

o chefe [1] mandou eles vai roubou 300 carros [...] o chefe [2] falou não hora...

No exemplo acima, é possível perceber a estratégia (1) de Anáfora Nominal, pois há a repetição de um item lexical - chefe - já escrito anteriormente.

\section{Exemplo 2: Anáfora Pronominal}

1- O ladrões [1] vai pegar o professor o tesouro. Eles [2] voi encontrou...

A estratégia (2), de Anáfora Pronominal com características de correferencialidade, foi usada nesse texto, uma vez que o referente - os ladróes - foi retomado pelo uso do pronome - eles.

\section{Exemplo 3: Anáfora Nominal}

Eu [1] vou escreve o e-mail está computador [...] Gabriel [2].

Nesse exemplo pode-se evidenciar a estratégia (3), de Anáfora Nominal, na qual o texto se inicia pelo uso do pronome de $1 .{ }^{\text {a }}$ pessoa, sendo posteriormente retomado pelo nome próprio - Gabriel.

\section{Exemplo 4: Anáfora Nominal por uso de sinonímia ou paráfrases}

o médico [1] muito demorar fila no hospital [...] o dr [2] experimenta...

Quanto à estratégia (4), de Anáfora Nominal pelo uso de sinonímias ou paráfrases, o exemplo 4, retirado do texto de um surdo, evidencia que inicialmente o sujeito usa o termo médico, retomado pelo uso de uma sinonímia - doutor. 


\section{Exemplos 5: Descrição Definida}

Os homens mal [1] voi pegar [...] o ladrões [2] vai pegar o pofessor o tesouro.

O sapo [1] é surdo. [...] O filho [2] não ouviu.

A estratégia (5), de Descrição Definida, é tomada por Koch e Marcuschi (2002) como forma lingüística constituída, minimamente, de um determinante definido, seguido de um nome. A escolha das expressões definidas, como nos exemplos sublinhados acima pode levar o leitor a perceber informações relevantes sobre as crenças, opinióes, atitudes do produtor do texto, auxiliando-o na construção do sentido.

\section{RESULTADOS}

A partir da explicitação de diferentes estratégias e recursos de referenciação usados na escrita de sujeitos surdos, será apresentado, na seqüência, a análise de quatro textos produzidos pelos sujeitos dessa pesquisa: uma carta, duas narrativas de ficção e o resumo de um filme.

\section{TEXTo 1}

1- $O \underline{\text { tatu }}[1]^{1}$ tem fazer casa

2- $\underline{\text { tatu }}$ [2] pobre tem triste $\underline{\text { raposa }}^{2}$ [3] disse desprezou triste

3- $\underline{\text { tatu }}[4]$ tem vi raposa [5] casa palacete nova. [6]

4- Raposa [7] conversou rei leão [8] palacete casa [9] tatu [10] fera

5- rei leão [11] vi casa [12] raposa [13] palacete [14] ? [15] mandou raposa [16] embora chuva

6- raposa [17] triste por favor tatu [18] casa [19] posso dormir tatu [20] sim casa [21] pode.

Esse texto foi produzido no dia 10/09/02, após a fonoaudióloga e o sujeito surdo terem lido uma história.

1 As cadeias anafóricas dos textos serão demonstradas por um número entre barras e os referentes serão sublinhados.

2 As palavras negritadas são aquelas que o sujeito perguntou por meio da língua de sinais como escrever. 
Do texto 1 foram selecionadas cinco cadeias anafóricas: uma para o referente "tatu", outra para "raposa", outra para "palacete", outra para "casa" e outra para "rei leão".

Para o referente "tatu" optou-se pela estratégia (1) postulada por Koch e Marcuschi (2002), de Anáfora Nominal com repetição lexical, em [2], [4], [10], [18] e [19].

Com relação ao referente "raposa", foi utilizada a estratégia (1), da referenciação especificada por Anáfora Nominal, em [5], [7], [13], [16] e [17].

No que diz respeito ao referente "palacete", é possível perceber, da mesma forma, a estratégia (1), de Anáfora Nominal, em [9], [12] e [14]. Verifica-se, porém, que apenas em [14] ocorre uma repetição lexical; nos outros exemplos a repetição é somente parcial.

Para o referente "casa", foi utilizada a estratégia (1), de Anáfora Nominal, em [21]. Essa cadeia referencial pode causar certa estranheza em leitores que não conhecem a história, já que pode ser confundida com a cadeia anterior. Como a terapeuta conhecia a história, sabia que a primeira "casa" que foi referida no texto era a "casa da raposa" e a "casa" desta cadeia era a "casa do tatu". Góes (1999) descreve alguns problemas com relação a instâncias de referencialidade ambígua na escrita de surdos, que podem causar prejuízo na interpretação do referente.

E, finalmente, para o referente "rei leão", também foi utilizada a estratégia (1), de Anáfora Nominal, em [11], assim como a estratégia (2) de Anáfora Pronominal pela elipse, em [15].

No texto 1 , verifica-se que, apesar de serem usados muitos referentes, pois estava sendo recontada uma história com quatro personagens, o autor do texto utilizou basicamente a estratégia (1), de Anáfora Nominal por repetição lexical. A estratégia (2), de Anáfora Pronominal, aparece apenas uma vez nesse texto. Nessas estratégias, a relação entre os termos se estabelece por correferência e co-significação; além disso, a abundância de repetições é, segundo Koch (1995), uma estratégia comum nas escritas iniciais, nas quais geralmente os aprendizes não sabem ao certo que estratégia usar e como modificar o seu uso.

Quanto à progressão referencial do texto 1 pode-se, então, afirmar que não ocorreram mudanças significativas nas estratégias utilizadas no texto selecionado. A estratégia (1), de repetição lexical por meio das anáforas nominais, foi a mais usada. Além disso, é possível verificar a estratégia (2), de Anáfora Pronominal, que, segundo Marcuschi (1998), freqüentemente ocorre na escrita, mas não é a preferencial e nem a mais comum. 


\section{TeXTo 2}

1- A Caroline [1]

2- Oi, tudo bem?

3- Meu nome é Gabriel [2]. Eu [3] tenho 15 anos. Meu [4] anivesário é 30/03. É o seu [5]?

4- Se você [6] quise ao cinema? É pra você [7] escolhe em qual? Tanto faz no shopping.

5- Eu [8] posso ir na sua [9] casa?

6 Eu [10] quero conversar com você [11]!

7- Se você [12] esconha pode na minha [13] casa ou é a sua $[14]$ ?

8- Você [15] gosta de vídeo?

9- Você [16] gosta de bi cicleta? $\square$ [17] Pode andar de bicicleta o comigo [18]?

10- Vamos, nós juntos comigo na andar.

11- Se você [19] quer combinar ao sábado $\underline{\text { meu }}$ [20] celular 99185756 e eu [21] tenho um e-mail: Gabriel@bbs2.com.br

12- Tchau! Gabriel H. [22]

O texto 2 foi elaborado no dia 13/11/02, a partir da vontade manifesta pelo sujeito em escrever uma carta para uma menina ouvinte.

Quanto às cadeias anafóricas desse texto, foram selecionados os referentes "Gabriel" e "Caroline".

Para o referente "Gabriel" ocorreu predileção pela estratégia (2), de Anáfora Pronominal com características de correferencialidade, em /eu/ [3], /meu/ [4], /eu/ [8], /eu/ [10], /minha/ [13], /comigo/ [18], /meu/ [20] e / $\mathrm{eu} /[21]$. É interessante notar a ocorrência de referenciação por pronomes demonstrativos nesse texto, talvez em função do gênero textual - carta. Foi possível verificar, também, o uso da anáfora nominal (1) por Repetição Lexical, em [22].

Quanto ao referente "Caroline", percebemos o uso da estratégia de anáfora pronominal em /seu/ [5], /você/ [6], /você/ [7], /sua/ [9], /você/ [11], /você/ [12], /sua/ [14], /você/ [15], /você/ [16], Æ [17] e /você/ [19]. 
Quanto à progressão referencial, no que diz respeito aos aspectos e às estratégias propostas por Koch e Marcuschi (2002), verifica-se que as estratégias (1) e (2) são as mais usadas. Convém salientar que a estratégia (2), de Anáfora Pronominal, não é mera repetição, mas tem função de correferencialidade. Essa mesma estratégia também foi bastante utilizada por meio das elipses.

\section{TEXTo 3}

1- Porque o Patinho [1] Feio.

2- Pata mãe é triste cuidava o patinho [2] e triste porque ele rir porque o patinho [3] feio.

3- coitado o patinho [4] é o pobre muito fome.

4- O patinho [5] é sozinho ficou cansado, com fome e com medo e o dormiu.

5- O pato selvagem é brincavam alegria.

6- O pato medo fugiu é sozinho o patinho [6].

7- O patinho [7] comeu peixe depois crasce forte.

8- O Cisne veio encontrou e o cisne amigo.

9- O $\underline{\text { Cisne }}$ [8] viu o água diverente o Pato [9].

Texto produzido no dia 14/05/01, após a terapeuta e o sujeito surdo terem lido juntos a história "Patinho Feio".

Nesse texto, foi selecionada apenas uma cadeia anafórica para o referente "patinho". Percebemos a estratégia (1) - Anáfora Nominal por repetição lexical - em [2], [3], [4], [5], [6] e [7]. Também, a estratégia (4), de Anáfora Nominal por sinonímia, em /pato/ [9] e a estratégia (5), de Descrição Definida, em /cisne/ [8].

Nota-se, nesse texto, assim como nos dois anteriores, que a estratégia (1) é bastante usada. Porém, diferentemente dos outros dois, as estratégia (4) e (5) aparecem no texto 3. Na análise dessa produção textual, é possível verificar que a cadeia anafórica é bastante elaborada, já que apresenta três estratégias para referenciação, inclusive estratégias de recategorização.

Entretanto, no texto 3, aparecem casos de referência ambígua. Na linha 2, na escrita de /ele rir/, tem-se a impressão de que era o próprio patinho feio que ria. Como a terapeuta estava junto no momento da produção e conhecia a história, sabia que foi outro pato que riu do patinho feio. 
Porém, da forma como o texto foi escrito, outro leitor poderia colocar o pronome "ele" nesta cadeia anafórica. Da mesma forma, na linha 6, a escrita de /o pato medo fugiu/, referia-se ao pato selvagem, que fugiu com medo do barulho de tiro, e não ao patinho feio. Também nas linhas 8 e 9, a palavra / cisne/ aparece três vezes. Contudo, somente na linha 9 refere-se ao patinho feio, quando este finalmente percebeu que era um cisne. Só foi possível determinar as referências ambíguas devido ao fato de a terapeuta ter partilhado a construção do texto; de outra maneira isso poderia ter causado prejuízos na coerência textual.

\section{TeXTo 4}

1- Dr. Do Little 2 [1]

2- O urso [2] é bonito.

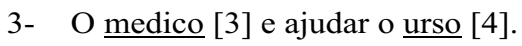

4- Ele [5] falou o Urso [6] aprende no floresta.

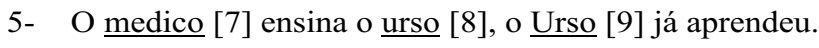

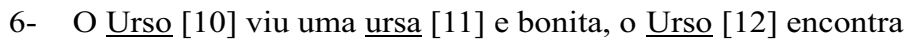
a ursa [13] sempre junto brinca.

7- O homem mal [14] atira o Urso [15], a ursa [16] foi esconde no trás a árove. $\mathrm{O} \underline{\text { Urso }}$ [17] fico dormir.

8- O homem mal [18] pega a Urso [19] levo na Loja, ele [20] fez bagunça na Loja.

9- A mulher viu o Urso [21] fez na Loja.

10- A ursa [22] ficou esperando o Urso [23].

11- O urso [24] foi preso.

12- Tudo os animais [25] fez greve.

13- Cavalo [26] não ir correndo.

14- Cachorro [27] não ir pega pau.

15- Vaca [28] não fez leite.

16- Gahinha [29] não fez ovos, joga o homem.

17- Juiz viu como as animais [30] fez greve.

18- As animais [31] diz eles [32] quer mora floresta não corta a árvore.

19- O cachorro [33] ficou bravo o homem mal.

20- O Urso [34] live.

21- O Urso [35] casou a Ursa [36] fez dois Ursinho.

Texto produzido no dia 31/07/01, após a terapeuta e o sujeito surdo conversarem sobre o filme que haviam assistido no cinema: "Dr. Do Little II". 
Para a análise do texto 4, foram selecionadas cinco cadeias anafóricas: uma para o referente "Dr. Do Little", outra para "urso", outra para "ursa", outra para "homem mal" e, por fim, uma para "animais".

Para o referente "Dr. Do Little", houve predileção pela estratégia (5), de Descrição Definida /medico/, em [3] e [7], e pela estratégia (2), de Anáfora Pronominal, em /ele/ [5].

No que tange ao referente "urso", ocorreu a predileção pela estratégia (1), de Anáfora Nominal por repetição lexical, em [4], [6], [8], [9], [10], [12], [15], [17], [19], [21], [23], [24], [34] e [35]. Também pode-se acompanhar a retomada por meio da estratégia (2), de Anáfora Pronominal, em /ele/ [20].

Para o referente "ursa" é possível verificar apenas a estratégia (1), de Anáfora Nominal, em [13], [16], [22] e [36].

Com relação ao referente "homem mal" nota-se a retomada apenas uma vez, em [18], também por meio da estratégia (1), de Anáfora Nominal.

Por fim, para o referente "animais", foram usadas remissões, recategorizando a palavra, utilizando a estratégia (5), de Descrição Definida, em /cavalo/ [26], /cachorro/ [27], /vaca/ [28], /gahinha/ [29] e /cachorro/ [33]. Também é possível verificar a estratégia (1), de Anáfora Nominal, em [30] e [31] e a estratégia (2), de Anáfora Pronominal, em /eles/ [32].

As cadeias anafóricas usadas neste texto foram bem elaboradas, principalmente pelo uso da estratégia (5), de Descrição Definida, já que essa estratégia apresenta outras características, como a recategorização, a não correferencialidade, a não co-significação, a implicitação, a avaliação e a refocalização. Isso demonstra que o surdo que produziu esse texto está refletindo sobre o uso do português escrito, já que a referência é uma questão que envolve as operações efetuadas pelos sujeitos à medida que o discurso se desenvolve e constrói aquilo a que faz remissão, ao mesmo tempo em que é tributário dessa construção.

Conforme referido anteriormente, esses quatro textos ilustram a análise aqui realizada. Entretanto, além dessas quatro produções, foram consideradas outras doze que, somadas com as demais, totalizam dezesseis textos, os quais compõem o corpus de nossa pesquisa.

Nos dezesseis textos analisados foi encontrado um total de 42 cadeias anafóricas e 266 referentes. Desse número, 104 referentes, ou seja, $39,09 \%$ das estratégias de referenciação utilizadas nas cadeias anafóricas são identificadas como estratégia (1) de Anáfora Nominal por repetição lexical; 129 referentes, ou seja, $48,49 \%$, foram apresentados nos textos por meio da estratégia (2) de Anáfora Pronominal; 11 referentes, ou seja 4,13\%, foram encadeados nos textos pela estratégia (3) de Anáfora Nominal, cuja cadeia se inicia pelo uso de pronomes de $1 .^{\mathrm{a}}$ e $2 .^{\mathrm{a}}$ pessoas, retomados por nome 
próprio; 8 referentes, o que corresponde a $3 \%$ do total, dizem respeito a estratégia (4) de Anáfora Nominal pelo uso de sinonímias ou paráfrases. Por fim, a estratégia (5) de Descrição Definida, ocorreu em 14 referentes, correspondendo a 5,26\% das cadeias referenciais analisadas nos textos produzidos pelos sujeitos surdos. Na Tabela 1, apresentada na seqüência, é possível visualizar essas informações.

Tabela 1: Número e Porcentagem de Estratégias Utilizadas nas Cadeias REFERENCIAIS DOS DEZESSEIS TEXTOS ANALISADOS

\begin{tabular}{lll}
\hline $\begin{array}{l}\text { Estratégia utilizada nas cadeias } \\
\text { coesivas }\end{array}$ & Freqüência $(\mathrm{n}=266)$ & Porcentagem \\
\hline Anáfora Nominal (1) & 104 & $39,09 \%$ \\
Anáfora Pronominal (2) & 129 & $48,49 \%$ \\
Anáfora Nominal (3) - uso de & 11 & $4,13 \%$ \\
pronomes de 1. a 2. ${ }^{\text {a }}$ pessoas e & & \\
retomada por nome próprio & & \\
Anáfora Nominal - sinonímias (4) & 8 & $3 \%$ \\
Descrição Definida (5) & 14 & $5,26 \%$
\end{tabular}

A estratégia (1) de Anáfora Nominal por repetição lexical esteve presente em todos os dezesseis textos analisados e, além disso, foi a segunda estratégia mais utilizada. A estratégia (2) de Anáfora Pronominal apareceu em praticamente todos os textos, sendo a mais utilizada. A estratégia (3) de Anáfora Nominal, caracterizada pelo uso de pronomes de $1 .{ }^{\mathrm{a}}$ e $2 .{ }^{\mathrm{a}}$ pessoas retomados por nomes próprios, apareceu apenas em alguns textos, principalmente nas cartas e relatos, nos quais os sujeitos iniciaram sua escrita referindo-se a si mesmos pelo pronome eu e retomaram seus nomes no final do texto. A estratégia (4) de Anáfora Nominal por sinonímia apareceu poucas vezes nos textos analisados. E a estratégia (5) de Descrição Definida foi usada em alguns textos, totalizando catorze aparições. A média de uso de cadeias coesivas ou referenciais por texto produzido foi de 2,6. E a média de referentes apresentados pelos sujeitos surdos em cada texto foi de 16,6.

Além disso, cabe ressaltar que nos dezesseis textos a coerência só ocorreu pelo conhecimento de mundo e de língua compartilhados entre a investigadora e os sujeitos surdos. Assim, concordamos com Koch e Marcuschi (2002) quando afirmam que a coerência não se apresenta no discurso como algo pronto, estático, acabado, mas se constitui na interação dialógica e pressupõe uma disponibilidade dos interlocutores para encontrar um ponto comum de entendimento. 


\section{DISCUSSÃo}

Durante os dois anos de coleta dos dados foi possível participar como co-autora das produções textuais elaboradas pelos sujeitos surdos e não simplesmente aprovar ou corrigir os seus textos. Conforme Geraldi (1997), a produção de textos foi concebida como ponto de partida de todo o processo de ensino/aprendizagem da língua, pois é no texto que a língua se revela em sua totalidade. Desse modo, o sujeito compromete-se com sua palavra e com sua formação discursiva, e tem o que escrever, uma razão para escrever o que tem que escrever, para quem escrever, e constitui-se como tal, enquanto sujeito que escreve o que escreve para alguém ler.

Com relação à análise dos textos, dentre as estratégias de progressão referencial mais utilizadas, destacam-se duas: (1) Anáfora Nominal com repetição lexical e (2) Anáfora Pronominal. Essas estratégias são de referenciação especificada, ou seja, a relação entre os termos se estabelece por correferência. Além disso, os sujeitos da pesquisa fizeram uso, em alguns textos, da estratégia (3), de Anáfora Nominal, na qual a introdução ao referente ocorre pelo uso de pronomes de $1 .^{\mathrm{a}}$ ou $2 .^{\mathrm{a}}$ pessoa, e a retomada desses pronomes a partir de um nome próprio. Foi possível perceber, também, o uso da estratégia (4), de Anáfora Nominal por sinonímias e paráfrases. Essa estratégia exige a recategorização e a refocalização. Dentre as estratégias que requerem o uso implícito e supõem inferência por parte do leitor, os sujeitos empregaram em alguns momentos a estratégia (5), de Descrição Definida, que também é uma estratégia de recategorização, não correferencial, a qual demanda uma reflexão maior acerca da escrita para ser utilizada. Provavelmente, por isso que tal estratégia foi mais utilizada por sujeitos que estavam em séries mais avançadas.

A análise das produções textuais que compõem este estudo mostra, em conformidade com Pereira (2003), que os surdos constroem textos usando estratégias de referenciação com coerência e coesão, e que, por meio das trocas interacionais ocorridas a partir da língua de sinais com um interlocutor conhecedor da língua portuguesa e da Libras, o surdo pode interagir com esse interlocutor em ambas as línguas. Dessa forma, é possível afirmar que as interações por meio da língua de sinais, enquanto primeira língua dos surdos, propiciam o reconhecimento da relevância do uso de estratégias de referenciação e outros recursos expressivos próprios da língua portuguesa por parte desses sujeitos. 


\title{
RESUMO
}

Levando em consideração o número restrito de trabalhos que se propõem a analisar as produções textuais de sujeitos surdos e, também, o fato de que há poucas pesquisas envolvidas com o conhecimento que tais sujeitos têm sobre a compreensão e a produção de textos, o objetivo desta investigação é analisar dezesseis produções escritas por quatro sujeitos surdos à luz do conceito de referenciação, como proposto recentemente pela lingüística textual. Convém ressaltar que a progressão referencial, ou referenciação é um dos aspectos da textualidade capaz de conferir estabilidade e continuidade ao texto, sendo fator relevante para a coerência discursiva. $O$ resultado da análise das produções textuais que compõem este estudo mostra que os surdos constroem textos usando estratégias de referenciação e que, por meio das trocas interacionais com um interlocutor conhecedor da Língua Portuguesa, eles podem aprender a usar os recursos expressivos disponíveis nessa língua. Palavras- chave: adolescentes surdos; produção de textos; referenciação.

\begin{abstract}
There are few researchers that analyzes written productions of deaf individuals, also there are a restrict number of researchers that discuss the knowledge that these people have about written texts comprehension and production. In this way, the aim of this investigation is to analyze sixteen written productions of four deaf individuals based in the reference conception proposed recently by textual linguistic. It is important to show that the progression of references is one of the textual aspects that is capable to give stability and continuity to written productions, and it is also relevant to discursive coherence. The results of the written analyzes that are in this study show that deaf individuals can learn to use expressive resources that are disposable in Portuguese Language and can use reference strategies, as long as they have interactions with and interlocutor that knows this language.
\end{abstract}

Key-words: deaf adolescents; text production; reference. 


\section{REFERÊNCIAS}

FERNANDES, E. Problemas cognitivos e lingüísticos do surdo. Rio de Janeiro: AGIR, 1990.

FERNANDES, S. F. Surdez e linguagens: é possível o diálogo entre as diferenças? Dissertação (Mestrado) - Universidade Federal do Paraná, Curitiba, 1998.

GERALDI, J. W. Portos de passagem. São Paulo: Martins Fontes, 1997.

GÓES, M. C. R. Linguagem, surdez e educação. Campinas: Autores Associados, 1999.

GUARINELLO, A C. O papel do outro no processo de construção de produçóes escritas por sujeitos surdos. Tese (Doutorado) - Universidade Federal do Paraná, Curitiba, 2004.

KOCH, I. G. V. Aquisição da escrita e textualidade. Caderno de Estudos Lingüísticos, n. 29, p. 109-117, 1995.

KOCH, I. V.; MARCUSCHI, L. A. Estratégias de referenciação e progressão referencial na língua falada. In: ABAURRE, M. B. M.; RODRIGUES, A C. S. (Orgs.). Gramática do português falado. Campinas-SP: Unicamp, 2002. v. 8. 1998.

Processos de referenciação na produção discursiva. DELTA, n. 14, p. 169-190,

KYLE, J. G. Written language in a visual world. In: KEILL, B.; VANN, R. Exploring Speakingwriting relationships. England: Not Council Teachers of English, 1981.

MARCUSCHI, L. A. Aspectos da progressão referencial na fala e na escrita no português brasileiro. In: COLÓQUIO INTERNACIONAL - A investigação do português em África, Ásia, América e Europa: balanço e perspectivas. Berlim, Alemanha, 1998.

Da fala para a escrita: atividades de retextualização. São Paulo: Cortez, 2001.

MEIRELLES, V.; SPINILLO, A. G. Uma análise da coesão textual e da estrutura narrativa em textos escritos por adolescentes surdos. Estudos em Psicologia, v. 9, n. 1, p. 131-144, jan./ abr. 2004

MONDADA, L.; DUBOIS, D. Construction des objets de discours et catégorisation: une approche des processus de référenciation. Travaux neuchâtelois de linguistique, n. 23, p. 273-302, 1995.

PEREIRA, M. C. C. Discutindo o uso da sintaxe por estudantes surdos. In: BERBERIAN, A. P.; MASSI, G. A.; GUARINELLO, A. C. (Org.). Linguagem escrita: referenciais para a clínica fonoaudiológica. São Paulo: Plexus, 2003.

PEREIRA, M. C. C.; OLIVEIRA, C. L. A questão da autoria nas produções escritas de adolescentes surdos. In: SKLIAR, C. (Org.). Atualidade da educação bilíngüe para surdos. Porto Alegre: Mediação, 1999. v. 2.

RODRIGUES SILVA, I. O uso de categorias gramaticais na construção escrita de narrativas pelo sujeito surdo. Dissertação (Mestrado) - Universidade Estadual de Campinas, Campinas, 1998.

SILVA, M. P. M. A construção de sentidos na escrita do aluno surdo. São Paulo: Plexus Editora, 2001. 
